\title{
Variation in Carotenoid Composition in Carrots during Storage and Cooking
}

\author{
Chae Jin Lim', Hyun Young Kim, Cheol Ho Lee', Yongung Kim², Kyongwhan Back, \\ Jung-Myung Bae ${ }^{4}$, Shin Woo Lee ${ }^{1}$, and Mi-Jeong $\mathrm{Ahn}^{1 \dagger}$ \\ ${ }^{1}$ College of Life Sciences and Natural Resources, Jinju National University, Gyeongnam 660-758, Korea \\ ${ }^{2}$ College of Herbal Bio-industry, Daegu Haany University, Gyeongbuk 712-715, Korea \\ ${ }^{3}$ Department of Biotechnology, Agricultural Plant Stress Research Center, \\ Chonnam National University, Gwangju 500-757, Korea \\ ${ }^{4}$ School of Life Sciences and Biotechnology, Korea University, Seoul 136-701, Korea
}

\begin{abstract}
High-performance liquid chromatography (HPLC) was applied to determine the carotenoid composition of carrots during storage and cooking. Analyses were conducted immediately after harvest and 1, 2, 4, and 8 weeks after harvest. During the course of the storage, the carotenoid levels generally decreased, and this decrease was found to be greater during the first week for $\beta$-carotene (all-trans- $\beta$-carotene) and lutein, and during the second week for $\alpha$-carotene. Additionally, the amount of the $\alpha$ - and $\beta$-carotenes in carrot leaves changed slightly within the first 2 weeks of harvest when stored at $4^{\circ} \mathrm{C}$. Specifically, the level of lutein, the main component of carrot leaves, increased from $233.8 \pm 11.7$ to $346.2 \pm 26.7 \mu \mathrm{g} / \mathrm{g} \mathrm{DW}$ during the first 2 weeks. In addition, the change in carotenoid contents was observed during the home-processing of one Korean cultivar. Carrots fried in oil showed the highest amount of $\beta$-carotene $(164.3 \pm 6.6 \mu \mathrm{g} / \mathrm{g} \mathrm{DW})$ and $\alpha$-carotene $(50.1 \pm 0.4 \mu \mathrm{g} / \mathrm{g} \mathrm{DW})$, while carnots that were prepared by sautéing, pressure-cooking in water and microwaving had the second highest levels. The greatest loss of in carotenoids occurred in response to boiling in water containing $1 \% \mathrm{NaCl}$, braising and baking. The content of lutein increased slightly after boiling in water containing $1 \% \mathrm{NaCl}(9.3 \pm 0.4 \mu \mathrm{g} / \mathrm{g} \mathrm{DW})$, while a loss in lutein occurred after preparation using other home-processing methods. A cis-isomer of all-trans- $\beta$-carotene, 13-cis- $\beta$ -carotene, was present in detectable amounts in all processed samples, but not in raw roots. Another isomer, 9-cis- $\beta$-carotene, was detected in carrots that were prepared by boiling, frying and pressure-cooking.
\end{abstract}

Key words: carrots, $\alpha$-carotene, $\beta$-carotene, lutein, carotenoids, storage, cooking

\section{INTRODUCTION}

Carrots are the roots of Daucus carota L. (Apiaceae) and an important dietary source of carotenoids such as $\alpha$ - and $\beta$-carotenes (provitamin A). While carotenoid pigments are essential for photosynthesis and function as attractants in some higher plant organs, their health benefits to humans and animals are becoming increasingly apparent $(1,2)$. For example, there is a great deal of evidence that these pigments act as antioxidants and protect humans from serious disorders such as skin degeneration and aging, cardiovascular disease, certain types of cancer and age-related diseases of the eye, such as macular degeneration or cataracts (3-5). Indeed, the lutein extract from marigold flowers has recently been used as a supplementary nutrient to maintain the health of eyes.

As a food material, carrots are usually stored in domestic refrigerators for several weeks and home-proc- essed using various cooking methods. However, carotenoids are known to be labile to light or heat, oxygen and acids. Indeed, evaluation of the Japanese carrot variety Kintoki revealed that $20 \%$ of $\beta$-carotene (all-trans- $\beta$ carotene) content was lost within eight weeks of cold storage, and the content was found to decrease slightly after blanching at $90^{\circ} \mathrm{C}(6)$. Another study found that food processing reduced carotenoid contents in food materials and changed their chemical conformation (7). Additionally, the carotenoid content was found to decrease with increasing storage period in cooked carrots, and the 9- and 13-cis carotenoid isomers were the major components formed during storage (8). Although there have been several other reports conducted to evaluate the stability of carrots under different storage conditions, these studies do not provide much information regarding the stability of lutein or effect of various home-processing methods (9-11). In the present study, the stability of the major carotenoids in carrots was evaluated during

${ }^{\dagger}$ Corresponding author. E-mail: amj5812@jinju.ac.kr

Phone: +82-55-751-3228, Fax: +82-55-751-3229 
cold storage and several cooking processes by high-performance liquid chromatography (HPLC). The nutrient value of fresh carrot leaves was also evaluated.

\section{MATERIALS AND METHODS}

\section{Storage condition}

Freshly harvested carrots (Daucus carota L. cv. Bibari) grown in Kimhae, Korea, were purchased from the field in November, 2007. Prior to storage, the carrot leaves were cut, after which the roots and leaves were transferred to storage chambers set at $4^{\circ} \mathrm{C}$. Triplicate roots were then taken from the chamber, washed and freeze-dried for carotenoid analysis after 1, 2, 4, and 8 weeks. Leaves were analyzed after one and two weeks of storage. All of the lyophilized samples were stored at $-80^{\circ} \mathrm{C}$ until analysis.

\section{Home-processing methods}

Commercial carrots (average weight about $250 \mathrm{~g}$ ) purchased from a local market in January, 2008 were used in this experiment. Carrots were washed with tap water and dried with kitchen towels. Triplicate roots were then peeled and cooked by each home-processing method. After cooking, all samples were allowed to stand at room temperature for $30 \mathrm{~min}$ and then freeze-dried.

Baking: Samples (one root divided into 6 pieces) were wrapped with aluminum foil and then baked for $20 \mathrm{~min}$ in a microwave oven range (LG-MZ-945TL) that had been preheated to $200^{\circ} \mathrm{C}$.

Boiling: Three chopped fresh roots (one root divided into 6 pieces) were boiled for $15 \mathrm{~min}$ in distilled water $(100 \mathrm{~mL})$ containing $1 \mathrm{~g}$ of salt.

Braising: Distilled water $(100 \mathrm{~mL})$ was mixed with $10 \mathrm{~mL}$ of soy sauce and $3 \mathrm{~g}$ of sugar. Carrots (one root divided into 6 pieces) were added to an open pot of boiling water and braised for $15 \mathrm{~min}$.

Frying: Fresh carrots were chopped into $0.7 \times 1 \times 5$ $\mathrm{cm}$ pieces and then fried at $170^{\circ} \mathrm{C}$ for $3 \mathrm{~min}$ in $300 \mathrm{~mL}$ of oil.

Microwaving: Carrots were placed onto a plate and cooked at high heat for $10 \mathrm{~min}$ in a microwave oven with a power rating of $2450 \mathrm{MHz}$ (Daewoo-KOR-6355).

Pressure-cooking: Carrots were cooked at medium heat for $5 \mathrm{~min}$ in a pressure cooker (Kitchen Sense) containing $100 \mathrm{~mL}$ of distilled water and $1 \mathrm{~g}$ of salt.

Sautéing: Carrots were chopped into $0.3 \times 0.5 \times 5 \mathrm{~cm}$ pieces and then sautéed for $5 \mathrm{~min}$ with $5 \mathrm{~mL}$ of oil and $1 \mathrm{~g}$ of salt.

\section{Carotenoid analysis}

All extraction procedures were conducted under sub- dued light to avoid degradation loss of the pigments Two hundred fifty milligrams of the lyophilized samples were homogenized using a pre-chilled mortar and a pestle with $5 \mathrm{~mL}$ of acetone $(0.01 \%$ butylated hydroxytoluene, BHT), sea sand, $\mathrm{Na}_{2} \mathrm{SO}_{4}$, and $\mathrm{NaHCO}_{3}$. Extraction with acetone was repeated until the matrix became colorless. The extract was then centrifuged at $5,000 \mathrm{rpm}$ for $5 \mathrm{~min}$, after which the supernatant was filtered through a $0.45 \mu \mathrm{m}$ membrane filter (Whatman, PTFE, $13 \mathrm{~mm}$ ) and then subjected to HPLC analysis.

HPLC analysis was conducted using an Agilent 1100 HPLC system (Hewlett-Packard, Waldbronn, Germany) that consisted of a temperature controlled autosampler, column oven and binary pump. Ten-microliters of standard or sample solutions were directly injected onto a YMC $\mathrm{C}_{30}$ carotenoid column $(3 \mu \mathrm{m}, 4.6 \times 250 \mathrm{~mm}$, Japan $)$ with solvent $\mathrm{A}$ [methanol : tert-butylmethyl ether: water $(81: 15: 4, \mathrm{v} / \mathrm{v})$ ] and solvent B [methanol : tert-butylmethyl ether : water $(6: 90: 4, \mathrm{v} / \mathrm{v})]$ using a step gradient elution of $100 \%$ solvent $A$ for the first $15 \mathrm{~min}$, then $100 \%$ solvent $\mathrm{A}$ to $100 \%$ solvent $\mathrm{B}$ over the next 35 min. A conditioning phase $(50 \sim 60 \mathrm{~min})$ was then employed to return the column to its initial state. The flow rate was $0.7 \mathrm{~mL} / \mathrm{min}$ and the column temperature was $22^{\circ} \mathrm{C}$. The eluent was detected at $450 \mathrm{~nm}$ using an UV-Visible detector. The Chemstation software (HewlettPackard, Avondale, CA, USA) was used to operate this HPLC-DAD system.

Carotenoids were quantified using an external calibration method. Briefly, $1 \mathrm{mg}$ of each standard was dissolved in $10 \mathrm{~mL}$ dichloromethane containing $0.01 \%$ BHT. Working calibration solutions $(50,20,10,5.0,2.5$, $1.0,0.50,0.25,0.10,0.025 \mu \mathrm{g} \mathrm{mL}^{-1}$ ) were then prepared by diluting the stock solution of the external standards. Standards of lutein, 13 -cis- $\beta$-carotene, $\alpha$-carotene, alltrans- $\beta$-carotene and 9-cis- $\beta$-carotene were purchased from CaroteNature $(\mathrm{GmbH}$, Lupsingen, Switzerland). Under these chromatographic conditions, standard carotenoids produced peaks at $t_{\mathrm{R}}(\mathrm{min}), 21.3$ for lutein, 37.0 for 13 -cis- $\beta$-carotene, 37.5 for $\alpha$-carotene, 39.3 for all-trans- $\beta$-carotene and 40.7 for 9-cis- $\beta$-carotene. Methanol, water and tert-butylmethyl ether used in the HPLC system were all HPLC grade and other chemicals used in the carotenoid analysis were extra grade.

\section{Statistical analysis}

All contents were expressed as the means \pm standard deviations (SD) of triplicate determinations. Differences among samples were evaluated by one-way analysis of variance (ANOVA). The values were evaluated at the $5 \%$ significance level using two-sided tests. 


\section{RESULTS AND DISCUSSION}

\section{Carotenoid analysis}

All-trans- $\beta$-Carotene and $\alpha$-carotene are two major carotenoid components of carrots. The third principle carotenoid, lutein, is an oxygen containing xanthophyll biosynthesized from $\alpha$-carotene. 13- and 9-cis- $\beta$-carotenes are known to be formed during cooking processes (Fig. 1) $(8,12)$; therefore, in this study, HPLC was applied to determine the contents of these five carotenoids.

Calibration curves were constructed on three consecutive days by analysis of a mixture containing various concentrations of the five carotenoids and then plotting the peak area against the concentration of each reference
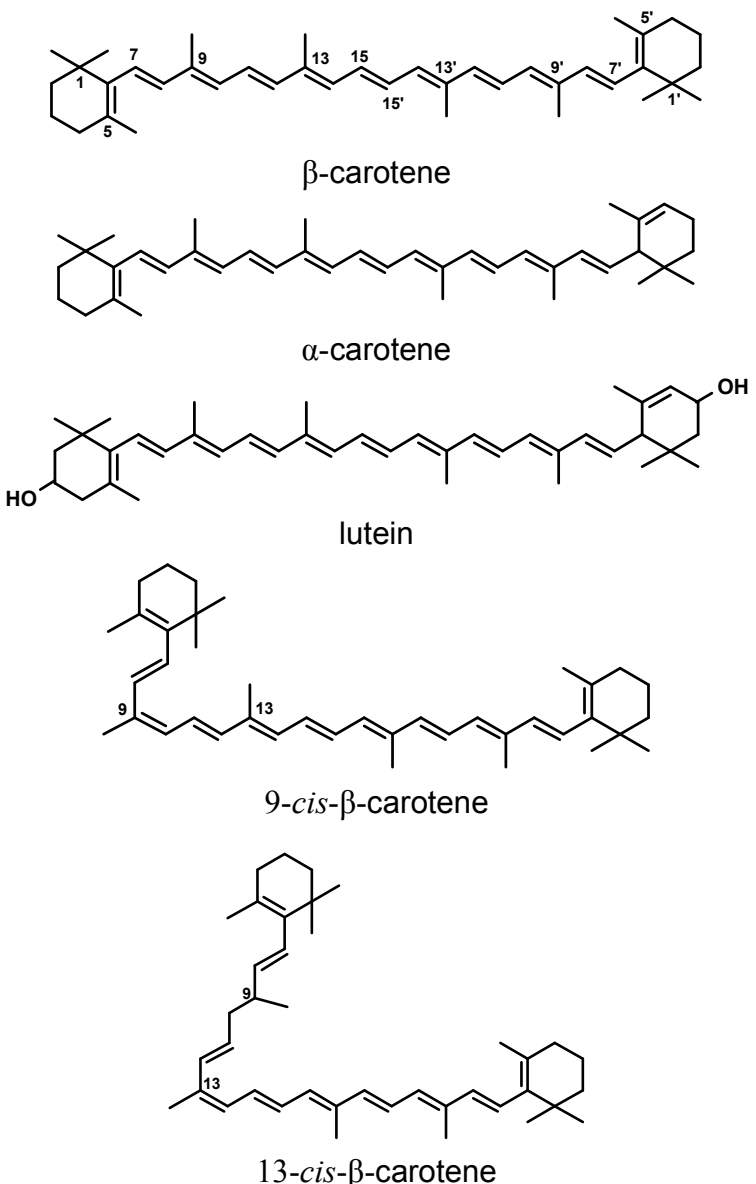

Fig. 1. Structures of carotenoids used in this study. standard (Table 1). The curves showed good linearity and the correlation coefficients were found to be in the range of $0.997 \sim 0.999$ for all compounds over the following concentration ranges: $0.03 \sim 12.5 \mu \mathrm{g} / \mathrm{mL}$ for lutein, 13- and 9-cis- $\beta$-carotenes, and $1 \sim 50 \mu \mathrm{g} / \mathrm{mL}$ for $\alpha$ carotene and all-trans- $\beta$-carotene. Additionally, the coefficient of variance $(\mathrm{CV})$ was less than $10 \%$ for the intra-day assays, but less than $19.2 \%$ for the inter-day assays. These results may have been due to the instability of the carotenoids. The recovery of five carotenoids was assessed by spiking the samples with high $(5,000 \mathrm{ng})$ and low $(50 \mathrm{ng})$ concentrations of each reference compound. The average recoveries were between 85.4 and $104.7 \%(n=3)$. The limits of detection (LOD) were determined by serial dilution based on a signal-to-noise $(S / N)$ ratio of 3:1 (Table 1).

\section{Variation in carotenoid composition during cold storage}

Carrots are generally consumed at home within several weeks of harvest, while fresh carrot leaves are discarded upon harvest and recycled as manure. In this study, the carotenoid composition of carrots and carrot leaves during cold storage was determined. Analyses were conducted at the time of harvest and 1,2, 4, and 8 weeks after harvest. For carrot leaves, the analyses were conducted at the time of harvest and 2 weeks after harvest. The leaves wilted after 2 weeks. During the experimental period, the carrots were stored in a domestic refrigerator at $4^{\circ} \mathrm{C}$.

The carotenoid levels in the carrots generally decreased during the storage period, and this decrease was found to be greater during the first week for all-trans- $\beta$ -carotene and lutein, while it was greater during the second week for $\alpha$-carotene. Within eight weeks of cold storage, the raw carrots lost approximately $53 \%$ of their initial total carotenoid content. Additionally, the alltrans- $\beta$-carotene content $(503.4 \pm 27.5 \mu \mathrm{g} / \mathrm{g} \mathrm{DW})$ was reduced to about $48 \%(260.1 \pm 18.9 \mu \mathrm{g} / \mathrm{g}$ DW), while $59 \%$ of the $\alpha$-carotene $(296.6 \pm 11.7 \mu \mathrm{g} / \mathrm{g} \mathrm{DW})$ and $60 \%$ of the lutein $(26.8 \pm 1.1 \mu \mathrm{g} / \mathrm{g} \mathrm{DW})$ was lost (Fig. 2). These results were consistent with the results of previous studies $(9-11)$.

Table 1. Linear ranges and correlation coefficients of calibration curves

\begin{tabular}{lccccc}
\hline Compounds & Range $(\mu \mathrm{g} / \mathrm{mL})$ & Slope $(a)^{1)}$ & Intercept $(b)^{2)}$ & Regression $\left(r^{2}\right)$ & LOD $(\mathrm{ng})$ \\
\hline Lutein & $0.03 \sim 12.5$ & 141.9 & 7.627 & 0.9998 & $\sim 0.1$ \\
13-cis- $\beta$-Carotene & $0.03 \sim 12.5$ & 219.5 & -13.23 & 0.9996 & $\sim 0.1$ \\
$\alpha$-Carotene & $1.0 \sim 50$ & 234.9 & -19.60 & 0.9978 & $\sim 0.1$ \\
all-trans- $\beta$-Carotene & $1.0 \sim 50$ & 204.1 & -32.79 & 0.9998 & $\sim 0.1$ \\
9-cis- $\beta$-Carotene & $0.03 \sim 12.5$ & 164.1 & -5.469 & 0.9968 & $\sim 0.1$ \\
\hline
\end{tabular}

${ }^{1,2)}$ Slope and intercept represent $a$ and $b$ in the $Y=a x+b$ linear model. $Y$ indicates the peak area and $x$ indicates the concentration. 
The amount of $\alpha$ - and $\beta$-carotenes in carrot leaves changed slightly within the first 2 weeks of storage at $4^{\circ} \mathrm{C}$. Specifically, the level of lutein, the main component in carrot leaves, increased from $233.8 \pm 11.7$ to 346.2 $\pm 26.7 \mu \mathrm{g} / \mathrm{g}$ DW during this period (Fig. 2). Although many studies have evaluated the carotenoid level of carrots, there have been no similar studies conducted to evaluate the carotenoid composition of carrot leaves. Generally, commercial supplementary nutrient products containing natural lutein are produced from the extraction of marigold flowers. Marigold flowers have concentrations of lutein esters of up to $161.0 \sim 611.0 \mathrm{mg} / 100$ $\mathrm{g}$ of flower DW, which is more than ten times higher than the content in carrot leaves (13). However, considering the amount of carrot leaves discarded in the field every year, these results show that carrot leaves may
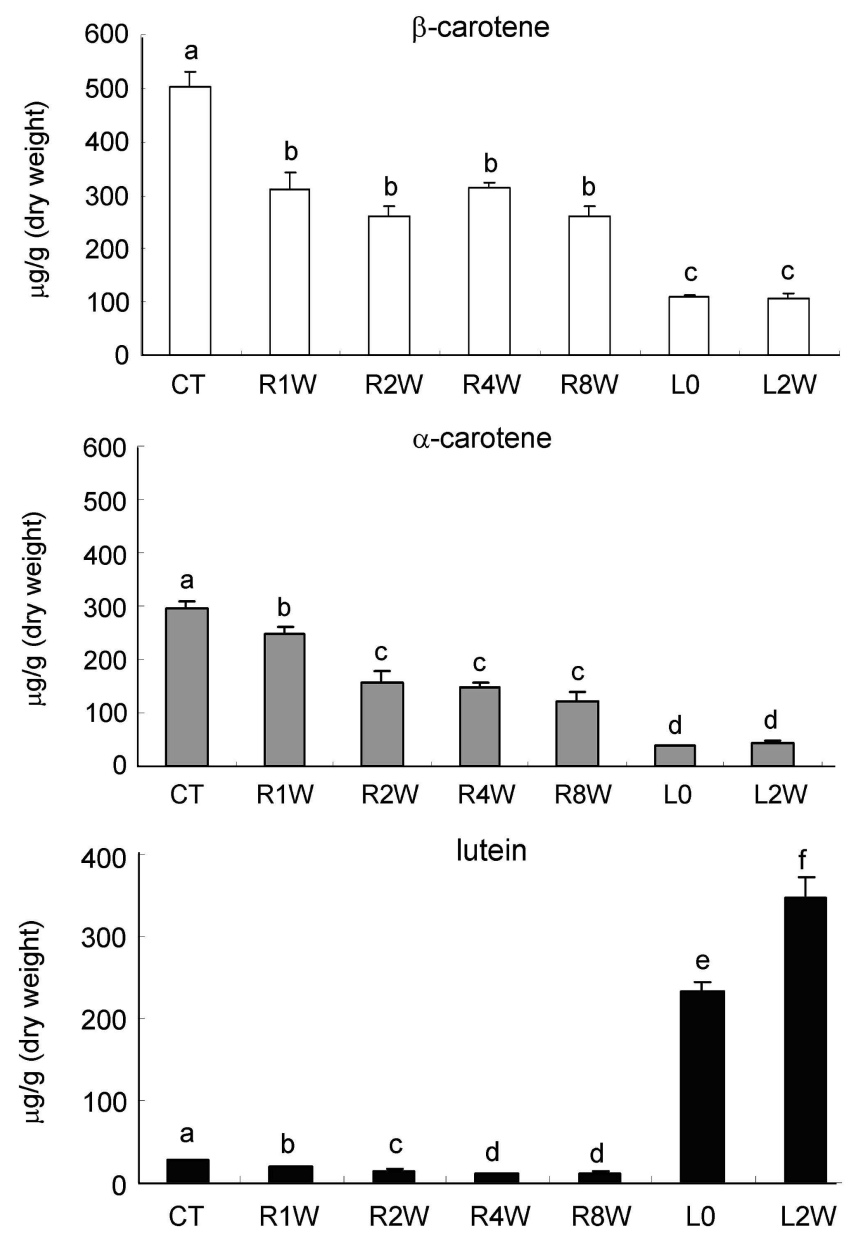

Fig. 2. Carotenoid stability in carrots during cold storage. Harvested and detached roots of a carrot variety, Bibari, were stored at $4^{\circ} \mathrm{C}$ in the dark for 0 (CT), 1 (R1W), 2 (R2W), 4 $(\mathrm{R} 4 \mathrm{~W})$ and 8 weeks $(\mathrm{R} 8 \mathrm{~W})$. Detached carrot leaves were stored under the same conditions for 0 (L0) and 2 weeks (L2W). The carotenoid contents are given as the means of three determinations of up to three different roots or leaves. Different letters indicate a significant difference $(\mathrm{p}<0.05)$ among samples. be a potential new source of lutein.

It should be noted that 13 - and 9-cis- $\beta$-carotenes which are known to be formed in heating process were not detected in these fresh roots and leaves throughout the experimental period (14).

Variation in carotenoid composition during cooking

Several representative cooking methods were applied to determine the variation of carotenoid content that occurs during processing (Fig. 3). Carrots fried in oil showed the highest amount of all-trans- $\beta$-carotene $(164.3 \pm 6.6$ $\mu \mathrm{g} / \mathrm{g} \mathrm{DW})$ and $\alpha$-carotene $(50.1 \pm 0.4 \mu \mathrm{g} / \mathrm{g} \mathrm{DW})$, while
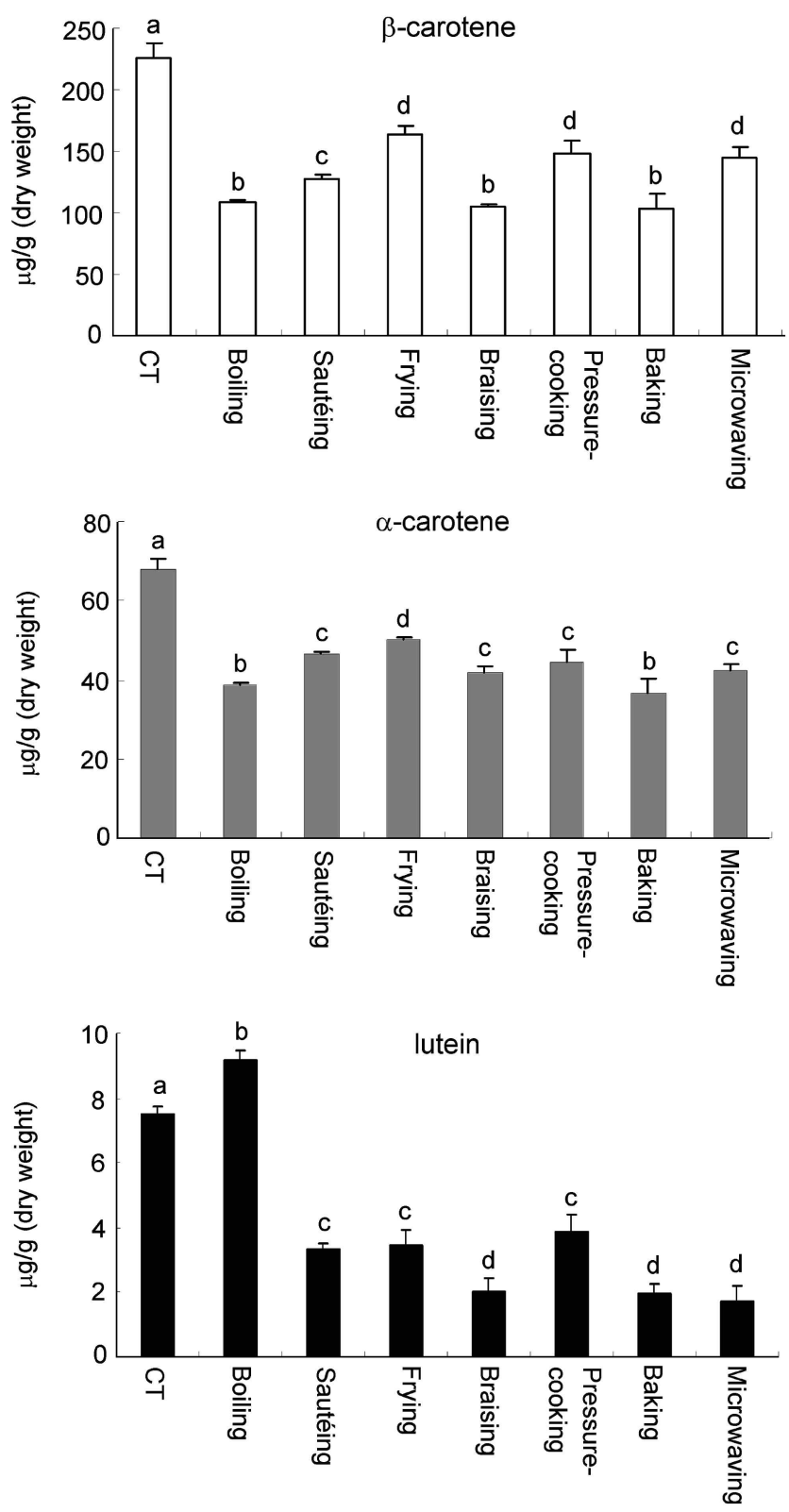

Fig. 3. Carotenoid stability in carrots during home-processing. The carotenoid contents are given as the means of three determinations of up to three different roots. Different letters indicate a significant difference $(\mathrm{p}<0.05)$ among samples. 
carrots that were prepared by sautéing, pressure-cooking in water and microwaving showed the second highest levels of these compounds. The greatest loss of these carotenoid components occurred during boiling in water containing $1 \% \mathrm{NaCl}$, braising and baking. These results showed that the loss of two major carotenoids from carrots might be correlated with the processing time. Specifically, longer exposure to heat and aquatic conditions may have resulted in a greater loss of these compounds. Conversely, the lutein content increased slightly after boiling in water containing $1 \% \mathrm{NaCl}$ $(9.3 \pm 0.4 \mu \mathrm{g} / \mathrm{g} \mathrm{DW})$, while it was reduced after preparation using the other home-processing methods.

During microwaving, the loss of lutein content was greater than the loss of $\alpha$ - and $\beta$-carotenes. This result is consistent with the results of a previous study in which the microwaving process decreased the lutein content more than the $\alpha$ - and $\beta$-carotene contents (15). A cis-isomer of all-trans- $\beta$-carotene, 13 -cis- $\beta$-carotene, was pres-
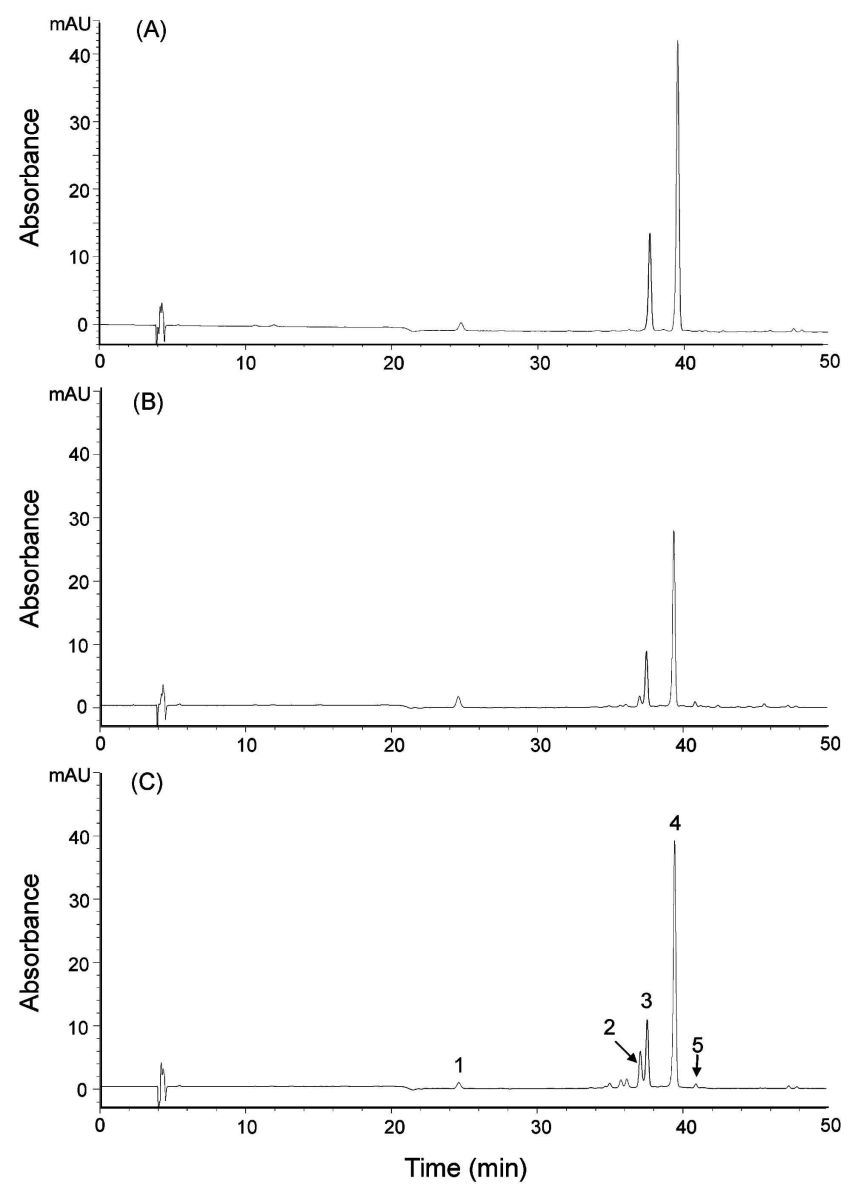

Fig. 4. Representative HPLC chromatograms recorded at 450 $\mathrm{nm}$ for measurement of carotenoid composition in the cooked carrots. (A) carrots before processing (control); (B) boiled carrots; (C) pressure-cooked carrots. The numbers of each peak indicate the following: 1 , lutein; 2,13 -cis- $\beta$-carotene; $3, \alpha-$ carotene; 4, $\beta$-carotene; 5, 9-cis- $\beta$-carotene. ent in detectable amounts in all processed samples, but not in raw roots, which indicates that 13- and 9-cis- $\beta$ -carotenes were formed during the cooking process. The greatest amounts of this isomer were formed during the pressure-cooking process $(22.9 \pm 3.5 \mu \mathrm{g} / \mathrm{g} \mathrm{DW})$. The content of 13-cis- $\beta$-carotene in other cooked samples was between $7.8 \pm 2.4 \mu \mathrm{g} / \mathrm{g}$ DW and $14.2 \pm 2.7 \mu \mathrm{g} / \mathrm{g}$ DW (Fig. 4). Another isomer, 9-cis- $\beta$-carotene, was detected in boiled, fried and pressure-cooked carrots at levels of $4.8,4.3$, and $4.7 \mu \mathrm{g} / \mathrm{g} \mathrm{DW}$, respectively.

Overall, the results of this study demonstrated that the carotenoid content of carrots did not differ significantly after two and eight weeks of cold storage. These results also demonstrated that all-trans- $\beta$-carotene, the major carotenoid in raw carrots, was retained in high levels when carrots were prepared using short-time processing methods.

\section{ACKNOWLEDGEMENTS}

This work was supported by a grant (Code 20070301034017) from the BioGreen 21 Program, Rural Development Administration, Republic of Korea, and partially by a Jinju National University grant, 2009.

\section{REFERENCES}

1. Deming-Adams B, Gilmore AM, Adams WW. 1996. Carotenoids 3: in vivo function of carotenoids in higher plants. FASEB J 10: 403-412.

2. van den Berg $H$, Faulks $R$, Fernando Granado $H$, Hirschberg J, Olmedilla B, Sandmann G, Southon S, Stahl W. 2000. The potential for the improvement of carotenoid levels in foods and the likely systemic effects. J Sci Food Agric 80: 880-912.

3. Rao AV, Rao LG. 2007. Carotenoids and human health. Pharmacol Res 55: 207-216.

4. Stahl W, Sies H. 2005. Bioactivity and protective effects of natural carotenoids. Biochim Biophys Acta 1740: 101-107.

5. Tapiero H, Townsend DM, Tew KD. 2004. The role of carotenoids in the prevention of human pathologies. Biomed Pharmacother 58: 100-110.

6. Mayer-Miebach E, Spiesz WEL. 2003. Influence of cold storage and blanching on the carotenoid content of Kintoki carrots. J Food Eng 56: 211-213.

7. Shi J, Le Maguer M. 2000. Lycopene in tomatoes: Chemical and physical properties affected by food processing. Crit Rev Food Sci Nutr 40: 1-42.

8. Kim H-Y, Lim Y, Russell RM. 2003. Changes in carotenoids contents in pureed and cooked carrot and spinach during storage. Korean J Soc Food Cookery Sci 19: 83-95.

9. Berger M, Küchler T, Maßßen A, Busch-Stockfisch M, Steinhart H. 2008. Correlations of carotene with sensory attributes in carrots under different storage conditions. Food Chem 106: 235-240.

10. Alasalvar C, Al-Farsi M, Quantick PC, Shahidi F, Wiktorowicz R. 2005. Effect of chill storage an modified 
atmosphere packaging (MAP) on antioxidant activity, anthocyanins, carotenoids, phenolics and sensory quality of ready-to-eat shredded orange and purple carrots. Food Chem 89: 69-76.

11. Çinar I. 2004. Carotenoid pigment loss of freeze-dried plant samples under different storage conditions. Lebensm Wiss Technol 37: 363-367.

12. Bengtsson A, Namutebi A, Larsson Alminger M, Svanberg U. 2008. Effects of various traditional processing methods on the all-trans- $\beta$-carotene content of orange-fleshed sweet potato. J Food Compost Anal 21: 134-143.
13. Li W, Gao Y, Zhao J, Wang Q. 2007. Phenolic, flavonoid, and lutein ester content and antioxidant activity of $11 \mathrm{cul}-$ tivars of Chinese marigold. J Agric Food Chem 55: 84788484.

14. Chen BH, Chen YY. 1993. Stability of chlorophylls and carotenoids in sweet potato leaves during microwave cooking. J Agric Food Chem 41: 1315-1320.

15. Chen BH. 1992. Studies on the stability of carotenoids in garland chrysanthemum (Ipomoea spp.) as affected by microwave and conventional heating. J Food Prot 55: 296-231.

(Received August 3, 2009; Accepted September 1, 2009) 